DOI https://doi.org/10.18551/rjoas.2020-12.24

\title{
SUSTAINABILITY STRATEGY OF MARINE CULTURE BUSINESS IN KEPULAUAN SERIBU
}

\author{
Nugrahadi Haris Achmad \\ Business School, IPB University, Indonesia \\ Zulbainarni Nimmi* \\ Business School, IPB University, Indonesia \\ Adrianto Luky \\ Department of Aquatic Resources Management, Faculty of Fisheries and Marine Science, \\ IPB University, Indonesia \\ *E-mail: nimmiz reims@yahoo.com
}

\begin{abstract}
Marine culture business is an alternative profession that has a positive impact on Kepulauan Seribu society. One of the commodities being developed is hybrid grouper Epinephelus sp. Further research needs to be carried out to determine whether the running business is optimal and feasible to function. Cobb-Douglas model be used to determine optimization production, Stochastic Frontier Analysis model to estimate the risk of variable inputs uses, and investment analysis to determine business feasibility. The results showed that the marine culture business in Kepulauan Seribu was in a condition of increasing return to scale $($ RTS $=1.489)$ so that the variable input of livestock and rearing period needed to be increased and net cage (KJA) and labor needed to be reduced so that production was an optimal. The variable inputs of livestock, rearing period, and labor are risk decreasing while the KJA variable is risk increasing. The feasibility analysis is divided into three clusters with positive investment values, namely cluster 1 (Panggang and Kelapa Dua sub-district) NPV Rp. 9,101,233,927, IRR 122\%, Net B/C 3.9, PP 3.2 years; cluster 2 (Tidung and Pari subdistrict) NPV Rp 2,937,199,206, IRR 127\%, Net B/C 4, PP 3 years; and cluster 3 (Lancang sub-district) NPV Rp. 2,189,009,750, IRR 107\%, Net B/C 3.4, PP 3.7. Resulting alternative strategies using blue ocean strategy is to reduce the use of net cage, eliminate non-hybrid livestock grouper input, raise hybrid livestock grouper and investors, and create a market integration of live hybrid grouper in Kepulauan Seribu.
\end{abstract}

\section{KEY WORDS}

Marine culture, Kepulauan Seribu, grouper, optimization, feasibility, strategy.

Indonesia as a maritime country has great potential in the development of the fisheries sector. This sector provides a National GDP value of 6.25 percent in 2019 or IDR 62.24 trillion. The fisheries sub-sector, namely aquaculture based on the national fishery production chart, shows an increasing value. Aquaculture as a primary sub-sector is very potential to be developed, one of which is marine cultivation or marine culture. A marine culture commodity that has the potential to be developed and has high economic value is grouper. Rahmaningsih and Ari (2013) explain that tiger grouper, humpback grouper, hybrid grouper and mud grouper are superior grouper types. Afero (2012) added that grouper is a commodity export-oriented where the main market destinations are China, Singapore, Hong Kong, and Japan. BPS (2018) explains that the export value of Indonesian live grouper to Hong Kong in 2017 reached 165.87 tons. The three types of grouper with the highest demand are leopard coral grouper, mud grouper, and hybrid grouper with share values of USD 68,719, USD 18,945, and USD 17,580.

Kepulauan Seribu, one of the areas that is part of the capital city DKI Jakarta, developing a marine culture business. The geographical location which consists of small islands supports 
the management activities of marine culture. Five sub-districts namely Panggang Island, Kelapa Dua Island, Tidung Island, Pari Island and Lancang Island in 2019 contributed 21,952 kilograms of live grouper production with the most types of grouper, namely hybrid, tiger, leopard coral and humpback groupers. The trend of using hybrid livestock grouper in the Kepulauan Seribu region began in 2017. This was based on fish farmers' complaints that the use non-hybrid livestock (tiger grouper, humpback grouper, leopard grouper) had a long maintenance period. The advantages of using hybrid livestock grouper are high growth rates, strong resistance to disease, and rapid adaptation time to the environment.

The purpose of this research was to analyze the optimization of input using and the risk that could arise from the using of each other that had an effect on the production of hybrid grouper established. This is to determine whether the business position is in optimal conditions to obtain maximum profit. Financial and non-financial feasibility analysis as an effort to develop a business scale. Formulation of alternative strategies based on the results of the previous analysis to create a new curve in the marine culture business in Kepulauan Seribu with hybrid grouper commodities.

\section{METHODS OF RESEARCH}

The study was conducted for four months from February to May 2020. Primary data were obtained through the distribution of online questionnaires aimed at respondents who conducted marine culture activities with commodity hybrid grouper fish Epinephelus fuscoguttatus-lanceolatus. The sampling technique used in this study was snowball sampling method. A total of 96 respondents participated in filling out online questionnaires distributed through respondents who are scattered in five sub-districts of Kepulauan Seribu region that Panggang, Kelapa Dua, Tidung, Pari, and Lancang.

Primary data collection is done using an instrument in the form of an online questionnaire with the help of Google Form. Type of questions in this research consisted of both open-ended and closed-ended questions. The questionnaire was divided into three parts: screening, respondent profile, and the main questions related to research variables.

Respondent profile data includes age, last education, profession, experiences, and marine culture business undertaken. Optimization production is analyzed using CobbDouglas model, estimation of the risk of production input using Stochastic Frontier Analysis model. Feasibility is assessed financially with an investment value consisting of NPV, IRR, Net $B / C$, and payback period. While non-financial feasibility is assessed using Likert scale showing the Total Achievement of Respondents' (TCR). Based on the results of the previous analysis the strategy formulation was carried using Blue Ocean Strategy.

\section{RESULTS OF STUDY}

Respondents' demographic data include age, last education, profession, and experience managing marine culture activities. Based on the results, the average age of the fish farmers' is 40 years old, last education is senior high school, profession is fisherman, and the experience in managing marine culture is 10 years. Fish farmers' are divided into 26 groups spread across 5 sub-district of the Kepulauan Seribu region.

Cobb-Douglas model is used in this research to analyze production function. This model assumes the relationship of production factors consisting of livestock, net cages, rearing period, and labor with the production of hybrid grouper.

Table 1 - Estimation of Regression Parameters

\begin{tabular}{|c|c|c|c|}
\hline Variable & Coefficient & $p$-Value & VIF \\
\hline Constant & 1.324 & 0.000 & \\
\hline Life stock $\left(X_{1}\right)$ & 0.833 & 0.000 & 7.085 \\
\hline Net cage $\left(\mathrm{X}_{2}\right)$ & 0.172 & 0.000 & 7.490 \\
\hline Rearing period $\left(X_{3}\right)$ & 0.474 & 0.000 & 1.584 \\
\hline Labor $\left(\mathrm{X}_{4}\right)$ & 0.010 & 0.782 & 1.116 \\
\hline
\end{tabular}

$R$-Square $=0.979 ;$ Adjusted R-Square $=0.979 ;$ Standard Error $=0.065 ;$ Durbin Watson $=1.978$. 
Based on Table 1, obtained the regression coefficient value of each independent variable which is a production factor that is estimate to have an impact on production, then the linear regression equation function is:

$$
\begin{gathered}
\operatorname{Ln} Y=\ln 1.324+0.833 \ln X_{1}+0.172 \ln X_{2}+0.474 \ln X_{3}+0.010 \ln X_{4} \\
Y=3.758\left(X_{1}\right)^{0.833}\left(X_{2}\right)^{0.172}\left(X_{3}\right)^{0.474}\left(X_{4}\right)^{0.010}
\end{gathered}
$$

Number of regression coefficients from the independent variables used show the elasticity of production. According to Debertin (1986) the value of elasticity shows what happens to production results if all variable inputs change proportionally. This situation can be seen in economics of scale behaviour, namely decreasing return to scale (RTS $<1$ ), constant return to scale (RTS $=1)$, and increasing return to scale $(R T S>1)$. Total production elasticity value is 1.489 so that the marine culture business in an irrational area. This case shows that the marine culture business can still be improved to get optimal conditions so that obtained maximum profit.

Optimization is the use of the level of production factors that can maximize the benefits of resources. Application variable input of production is in optimal condition if quotient product marginal value (NPM) and production input price (BKM) amount 1. If the comparison value preponderant $\left(\mathrm{NPM}_{\mathrm{x} i} / \mathrm{BKM}_{\mathrm{xi}}>1\right)$ input variable usage is not optimal. Likewise if comparison value is smaller $\left(\mathrm{NPM}_{\mathrm{x} i} / \mathrm{BKM}_{\mathrm{xi}}<1\right)$ input variable usage is not optimal so that it needs to be reduced (Soekartawi 2002).

\begin{tabular}{|c|c|c|c|c|c|}
\hline Variable & bi & BKM (idr) & NPM (idr) & Optimal & Actual \\
\hline Output (kg) & & 90,000 & & 155,918 & 1,967 \\
\hline Livestock & 0.833 & 15,000 & 60,245 & 9,812 & 2,448 \\
\hline Net cage & 0.172 & $4,000,000$ & $2,342,469$ & 8 & 13 \\
\hline Rearing period & 0.474 & 358,800 & 403,463 & 234 & 208 \\
\hline Labor & 0.010 & 75,000 & 19,456 & 23,6 & 90,98 \\
\hline
\end{tabular}

Table 2 - Optimized Cobb-Douglas Function Model

Based on Table 2, the comparison of NPM/BKM value for the life stock variable is 4.02 and rearing period is 1.12. The use of life stock and the rearing period variables is not optimal (NPM/BKM > 1) so it needs to be increased. Median value of using life stock in actual condition is 2,448 fish per production cycle, which needs to be increased to 9,832 fish per production cycle in optimal condition. Similarly the use of the rearing period variable is not optimal so it needs to be increased. Media value of using the rearing period in actual condition is 208 day, it needs to be increased to 234 days per production cycle in optimal condition. Comparison of NPM/BKM value for the net cage variable is 0.59 and labor is 0.26 . The use of net cage and labor variables is not optimal (NPM/BKM $<1$ ) so it needs to be diminished. Median value of using a net cage in actual condition is 13 swath per production cycle, which need to be diminished to 8 swath per production cycle. Labor in this study refers to the time used in maintenance activity in one day. Median value of using labor in actual condition is 90.98 hours per production cycle, it needs to be diminished to 23.60 hours per production cycle. Optimal condition in improving the production of hybrid grouper in Kepulauan Seribu in this case is increased using livestock and rearing period variables, while net cage and labor variables diminished.

Optimal condition in production will be able to maximum profit to be obtained. Based on the optimization analysis, profit after optimization can be calculated. The profit gained after optimization is compared with the actual profit to find out the maximum benefit.

\begin{tabular}{|c|c|c|}
\hline \multirow{2}{*}{ Constituent } & \multicolumn{2}{|c|}{ Condition } \\
\hline & Actual (idr) & Optimal (idr) \\
\hline Total Revenue & $177,047,100$ & $14,032,620,000$ \\
\hline Total Cost & $170,173,900$ & $293,209,200$ \\
\hline Profit & $6,873,200$ & $13,739,410,800$ \\
\hline
\end{tabular}

Table 3 - Comparison of Profit in Actual and Optimal Condition 
Stochastic Frontier Analysis (SFA) model is used to formulate the risk function estimation. This model makes use of the Maximum Likelihood Estimator (MLE), dissimilar from Cobb-Douglas model which used the Ordinary Least Square (OLS). Number of independent variables used to estimate the risk function is adjusted to the production function that is livestock, net cage, rearing period, and labor. The same input variable is used again to determine the characteristic of each input variable whether it can increase or decrease risk in production of hybrid grouper in Kepulauan Seribu.

Table 4 - Result of the Risk Function Estimation

\begin{tabular}{llll}
\hline Variable & Coefficient & Standard-Error & T-Ratio \\
\hline Constant & 0.796 & 0.230 & 0.347 \\
Livestock & -0.137 & 0.973 & -0.140 \\
Net cage & 0.117 & 0.358 & 0.328 \\
Rearing period & -0.891 & 0.337 & -0.265 \\
Labor & -0.167 & 0.170 & -0.979 \\
Sigma-Squares & 0.682 & 0.117 & 0.581 \\
Gamma & 0.996 & 0.750 & 0.133 \\
\hline
\end{tabular}

Log likelihood function $=-0.555 ;$ L $R$ test the one-sided error $=0.121$.

Based on the analysis, input variables of livestock (-0.137), rearing period $(-0.891)$, and labor $(-0.167)$ obtainable tend risk decreasing or variables could reduce the risk in production if the input variables are increased during maintenance. The character of variables is risk decreasing known based on the results of the risk function estimation analysis where the coefficient value is negative. All of the input variables used do not show any significance to production risk, this can be seen from the $\mid T$-ratio $\mid<T$-tabel.

Financial feasibility is needed for fish farmers' in evaluating as well as developing a business scale unit being activities. Evaluating in financial feasibility is conducted to assess the level of income and investment. The calculation in the Kepulauan Seribu is divided by cluster. The determination of the cluster according to Soebagio (2010) is based on a combination of three components, namely geophysical conditions, economic activity, and social linkages.

Parameters analyzed to determine whether a business is financially feasible are Net Present Value (NPV), Internal Rate of Return (IRR), Net B/C Ratio, and Payback Period.

Table 5 - Investment Feasibility Value

\begin{tabular}{lllll}
\hline Cluster & NPV (idr) & IRR (\%) & Net B/C Ratio & PP (years) \\
\hline Cluster 1 & $9,101,233,927$ & 122 & 3.9 & 3.2 \\
Cluster 2 & $2,937,119,206$ & 127 & 4 & 3 \\
Cluster 3 & $2,189,009,750$ & 107 & 3.4 & 3.7 \\
\hline
\end{tabular}

Based on the results of the financial feasibility analysis in Table 5, it is known that the value of each variable for cluster 1 (Panggang and Kelapa Dua sub-district), cluster 2 (Tidung and Pari sub-district), and cluster 3 (Lancang sub-district). The value obtained is the cluster 1 has an value of NPV is IDR 9,101,233,927; IRR 122\%; Net B/C Ratio 3.9; PP 3.2 years, cluster 2 has an value of NPV is IDR 2,937,119,206; IRR 127\%, Net B/C Ratio 4; PP 3 years, and cluster 3 has an value of NPV is IDR 2,189,009,750; IRR 107\%; Net B/C Ratio 3.4; PP 3.7 years. Marine culture business which is divided into three clusters in Kepulauan Seribu area is said to be feasible to implement. This is based on a positive NPV value, IRR value is greater than the rate of investing return, and Net B/C Ratio value is above 1 where every 1 rupiah spent will provide the benefits. Payback Period (PP) is used as a reference for the time needed to capital payback.

Non-financial feasibility analysis out in looking at environment conditions that effect the best alternative decision-making process. According to Sucipto (2011) non-financial feasibility consist of several aspects, one of which is the market aspect. Respondents' answer are arranged using a Likert Scale with five levels, namely (1) strongly disagree, (2) disagree, (3) neutral, (4) agree, and (5) strongly agree. Indicators variables used in this study 
are replications of the model used in the study before. The results of the respondents' answers were then analyzed using SPSS application and interpreted using Total Achievements of Respondents' (TCR) method. The TCR scale of the answer range refers to the scale according to Riduwan (2010).

Table 6 - Analysis of Total Achievment of Respondents' (TCR) in Market Aspect

\begin{tabular}{lll}
\hline Statement & TCR (\%) & Category \\
\hline Demand for live grouper is high in 2020 & 72 & Fair \\
Sales to Jabodetabek area & 84 & Good \\
Quality produced according to consumer demand & 90 & Good \\
Sales of live grouper is straightforward & 62 & Poor \\
Marketing transportation cost are major trait & 84 & Good \\
Consumers come to site production directly to purchase & 67 & Fair \\
Production site is easly accessible to consumers & 77 & Fair \\
Carry out direct and digital marketing promotions & 73 & Fair \\
Goverment helps in marketing process & 75 & Fair \\
Coordination between fish farmers' to improve sales & 83 & Good \\
\hline
\end{tabular}

The results of the interpretation based on the analysis of the total achievement of respondents', the main obstacle faced by farmers is the difficulty of making sales due to the high transportation costs of sending live hybrid groupers. The difference in production locations which is quite far away makes marketing inefficient. Although the grouper produced is in accordance with consumer demand with good quality, namely weight per fish of 500 600 grams, free from disease and no body defects. The fish farmers' routinely coordinate with each other in other sub-districts of the Kepulauan Seribu region in finding a market to improve the sales. The market for hybrid grouper fish from the Kepulauan Seribu is distributed to the Jakarta, Bogor, Depok, Tangerang and Bekasi (Jabodetabek) areas.

The formulation of alternative strategies is based on analysis of production optimization, estimation of risk functions, as well as financial and non-financial business feasibility. Several factors that are used to be at optimal and sustainable conditions need to be improved and eliminated. The formulation of alternative strategies uses the Blue Ocean Strategy, which is a concept initiated by Kim and Mauborgne (2015) that serves as a dilemma-breaking or exchange between differentiation and low costs and in order to create a new value curve.

Blue Ocean Strategy has a concept, namely a four-action framework consisting of eliminate, reduce, raise, and create for the preparation of a sustainable business strategy.

Table 7 - Four-action Framework

\begin{tabular}{lll}
\hline Action & Strategy & Performance Improved \\
\hline Reduce & Net cage overcapacity & Environtment \\
Eliminate & Non-hybrid livestock grouper & Productivity \\
Raise & Hybrid livestock grouper & Optimization \\
& Investors & Business scale \\
Create & Integrated Market & Marketing \& promotion \\
\hline
\end{tabular}

\section{DISCUSSION OF RESULTS}

Marine culture business in the Kepulauan Seribu is carried out by the local society as an alternative job to fulfill the need for economy. Formulation of strategies so that these business activities are sustainable and provide benefits to the community support them. Blue ocean strategy is a concept to create a new curve in the marine culture business in Kepulauan Seribu with live hybrid grouper commodities. Alternative strategies formulation of the problem is based on the results of the production optimization analysis, estimation of the risk function on production inputs, as well as the financial and non-financial feasibility assessments conducted previously. There are five alternative strategies that can be applied based on the four action frameworks as follows. 
Based on the optimization results, several variable inputs must be reduced to obtain optimal conditions for live hybrid grouper production in Kepulauan Seribu. One of the input variables that must be reduced is the net cage (KJA). Production optimization is supported by the estimation of the risk function; the tendency characteristic of net cage is a risk increasing, where each additional use of the amount of net cage will increase the risk in production. The average use of KJA in producing hybrid grouper in Kepulauan Seribu is 13 swaths per cycle production. The optimal condition for using the average net cage after optimization is 8 swaths per cycle production. Reducing the use of net cage will reduce the risk of production.

According to Kartamiharja (2013) the used of net cage must observe at the carrying capacity and land suitability to avoid overcapacity which will have an impact on decreasing productivity. Overcapacity in an area will increase the volume of organic waste produced during the production process. The high volume of organic waste according to Sachoemar and Wahjono (2007) will cause waters to become very fertile and have the potential to trigger eutrophication and have an impact on decreasing dissolved oxygen content due to the respiration process. As a result, the cultivated hybrid grouper becomes oxygen deficient and plankton clogging of the gills. Apart from this, the overcapacity will also have the potential for an up-wheeling phenomenon in which the bottom water mass increases to the surface. Organic waste containing hazardous materials such as H2S and Ammonia that is produced will rise to the surface. This will cause mass mortality of groupers cultivated.

The obstacle encountered by fish farmers when using non-hybrid livestock grouper such as tiger grouper and humpback grouper is that it takes a long time to grow so that the production period is longer. This will have an effect on high operational costs, especially the cost of purchasing feed. The maintenance period for non-hybrid grouper such as tiger grouper is $12-14$ months and humpback grouper $24-28$ months. The selling price for tiger grouper is IDR 100,000 per kilogram, while the humpback grouper is IDR 450,000 per kilogram. The use of hybrid livestock grouper is a solution in overcoming these matters. Hybrid grouper is the result of cross-breeding tiger grouper Epinephelus fuscoguttatus which has a strong immune system against disease with giant grouper Epinephelus lanceolatus which has a fast growth rate. The maintenance period for hybrid grouper is also shorter so that it is the choice of cultivators in Kepulauan Seribu to use as the main commodity. The maintenance period for hybrid grouper is $6-8$ months with a selling price of IDR 90,000 per kilogram. The application which was started in 2017 also provides positive values with high production reaching 57,361.3 kilograms during 2017 - 2019 compared to non-hybrid grouper species. Based on the calculation of the actual production function, the use of hybrid livestock grouper input provides an average profit of IDR 6,873,200 per production cycle.

The advantages of hybrid grouper, according to Luthfiyah and Budi (2019) are high growth rates that accelerate the maintenance period, have a strong immune system against disease, and a rapid adaptation period to new environments. This has an effect on increasing the value of productivity when entering the harvest period so that the benefits obtained are more than the non-hybrid grouper cultivation. Farmers can eliminate the use of non-hybrid livestock grouper and use hybrid livestock grouper to create a new curve in the Kepulauan Seribu region. It can be focused and become one of the hybrid grouper producing areas in Indonesia.

Livestock is the main input variable in conducting cultivation, when there is not available livestock, nothing that can be maintained so that it cannot produce. Based on the results of optimization, livestock is one of the input variables that needs to be increased. The increasing number of livestock used per production cycle will cause hybrid grouper production in Kepulauan Seribu to be at optimal conditions. The estimation of the risk function for the livestock input variable is also tend characteristic risk decreasing where any increase in the livestock will be able to reduce the risk of hybrid grouper production in Kepulauan Seribu. The average use of hybrid livestock grouper in Kepulauan Seribu in actual conditions is 2,448 fish per production cycle. Increase the average use of livestock in order to create optimal conditions to 9,832 fish per production cycle. Fish farmers' get grouper livestock from two sources, namely government assistance and independent 
purchases. Purchases made independently of the Kepulauan Seribu such as Situbondo and Lampung.

Increasing the use of livestock must also pay attention to the appropriate intensiveness so as not to decrease productivity to avoid cannibalistic characteristics of the hybrid grouper itself due to being too dense in one swath of KJA. Fish farmers' in Kepulauan Seribu conduct an intensiveness of 200 - 300 fish per plot. According to Folnuari et al. (2017) the density of hybrid grouper as many as 225 fish per swath of KJA is still tolerable, although not optimal. The intensiveness of 225 fish will have an impact on the survival rate (SR) of $93.3 \%$, the increase in absolute weight (W) is 79.15 grams, and the specific growth (SGR) is $3.45 \%$. Increasing intensity, the value of the survival rate, the addition of absolute weight, and the specific growth will decrease. According to Kadarini et al. (2010) a high stocking density can cause stress for fish, this condition can cause metabolism to be stunted and fish appetite to decrease. The high intensiveness also causes competition for space, feed, and dissolved oxygen which affects the normal function of the fish, thereby inhibiting growth and conduce to death.

Based on the analysis of the financial feasibility of the marine culture business in Kepulauan Seribu, it can be feasible to implement. The marine culture business in Kepulauan Seribu is divided into three clusters. Cluster 1 consists of Panggang and Kelapa Dua sub-district, cluster 2 consisting of Tidung and Pari sub-district, and cluster 3 is Lancang sub-district. The investment feasibility value in the three clusters is positive, where the business activities that are carried out generate value in terms of benefits and finances. Although the development of a business scale is still obstructed. The fish farmers carry out these activities using private funds to manage the activities. This becomes a detention because the profits earned are usually used to start the next production cycle. Investors or partnerships are required in helping fish farmers' funding in Kepulauan Seribu in developing a marine culture business scale. The results of the financial feasibility analysis can be used as a reference in seeing the potential that can be generated from this activity. The government of DKI Jakarta is also needed in finding investors and partnerships in helping to fish farmers' funding to manage the marine culture business in Kepulauan Seribu.

A non-financial analysis of the market aspects for hybrid groupers produced in Kepulauan Seribu get advantages and disadvantages. The advantage value is product that the quality of the hybrid grouper is in accordance with consumer demand, weight per fish is 500 - 600 grams, free from disease, and body in perfect condition or not deformed. Moreover in increasing sales, fish farmers' in Kepulauan Seribu conduct coordination to find potential markets in selling the products. Potential markets including Jakarta, Bogor, Depok, Tangerang and Bekasi (Jabodetabek) areas. However, the weakness is that the production locations are scattered in the Kepulauan Seribu area and have a long distance from each other. This makes it difficult for fish farmers' to sell because of the high cost of transporting live grouper to consumers. Likewise, consumers have difficulties when they want to make a purchase at production areas because of the spread of production area and different prices in one sub-district and other.

The solution to overcome these issues is the development of an integrated market. The government can help build an integrated market so that fish farmers' have no difficulty in marketing their products and consumers are not difficult when they come directly to the location to buy the product. The existence of an integrated market will be an indicator of marketing efficiency for live hybrid grouper in Kepulauan Seribu.

According to Suarez (2000) the formation of market integration in an area is shown to allocate resources more efficiently, encourage competition, and increase economies of scale in production and distribution between these regions. Meier (1995) added that market integration will produce several benefits for the regions that apply it, such as encouraging the development of local industries, increasing the benefits of trade through improved terms of trade, and encouraging economic efficiency in a region. Asmarantaka (2012) also states that market integration is an indicator to determine marketing efficiency. The measure of efficiency is the satisfaction of consumers, producers, and institutions involved in the flow of goods or services from cultivators to end consumers. 


\section{CONCLUSION}

Marine culture has provided economic income for the local society in Kepulauan Seribu. The production of marine culture that has been processed has not been optimal so that maximum profit is not achieved. One of the applications to optimize marine culture production in Kepulauan Seribu is to escalate the number of hybrid livestock grouper uses and eliminate the non-hybrid livestock grouper. Escalate the livestock uses will also be able to reduce the risk of production. Moreover to avoid the risk of production, must reduce the use of net cage so that avoid overcapacity in an area. The average profit obtained under optimal conditions is IDR 13,739,410,800. Marine culture business in Kepulauan Seribu can also be said to be feasible to implement. The results of the investment feasibility analysis show the value of NPV, IRR, and Net B/C Ratio which are positive. This can be used as a reference as input for getting investors to increase the scale of the marine culture business in Kepulauan Seribu. The development of an integrated market will also assist fish farmers' in maximizing the marketing of hybrid grouper products. The integrated market that is built will provide benefits to encourage the development of the hybrid grouper industry, increase trade benefits, and promote economic efficiency in Kepulauan Seribu.

\section{RECOMMENDATIONS}

Implementing policies and providing education on the importance of using net cage which must be adjusted to the capacity of carrying capacity so that production failure and environmental damage do not occur. The construction of a hatchery to supply the demand for hybrid livestock grouper so that fish farmers' do not need to buy from outside the Kepulauan Seribu area. Further study on production efficiency and the factors that influence the inefficiency and risk preference of fish farmers' to hybrid grouper production. The study is more closely related to the analysis of market integration and determinants at the producer level of hybrid grouper marketing in Kepulauan Seribu.

\section{REFERENCES}

1. Afero F. (2012). Economic Analysis of Tiger Grouper Epinephelus fuscoguttatus and humpback grouper cromileptes altivelis on net cages in Indonesia. Depik. 4 (1) : $11-23$.

2. Asmarantaka SW. (2012). Sales of Agribusiness (Agrimarketing). Department of Agribusiness. Faculty of Economics and Management. IPB University.

3. [BPS] Statistics Indonesia. (2018). Kepulauan Seribu in Numbers. BPS Kepulauan Seribu Regency.

4. Debertin DL. (1986). Agricultural Production Economics (The Art of Production Theory). Kentucky (US): University of Kentucky.

5. Folnuari S, Rahimi SA, Rusydi I. (2017). The Effect of Different Intensiveness on the Survival Rate and Growth of Cantang Grouper Epinephelus fuscoguttatus-lanceolatus on HDPE Material of Net Cage Technology. Scientific Journal of Marine and Fisheries Student Syah Kuala University. 2 (2) : 310 - 318.

6. Kadarini T, Sholichah L, Gladiyakti M. (2010). The Effect of Intensiveness on Survival Rate and Growth Ornamental Fish Silver Dollar Metynnis hypsauchen in the Recirculation System. Proceedings of the Aquaculture Technology and Innovation Forum.

7. Kartamiharja ES, Purnomo K, Tjahjo DW, Koehendradjana S. (2013). Ecosystem Approach for the Management of Arowana Irian Scleropages jardinii Fish Resources in Maro River, Merauke-Papua. Journal of Indonesian Fisheries Policy. 5 (2): 87 - 96.

8. Kim WC and Muborgne R. (2015). Blue Ocean Strategy: How to Create Uncontested Market Space and Make the Competition Irrelevant. Massachusetts (US): Harvard Business Review Press.

9. Luthfiyah L and Budi DS. (2019). Asymmetry Fluctuation of Hybrid Grouper Epinephelus fuscoguttatus x Epinephelus lanceolatus from Situbondo. Journal of Aquaculture Science. 
4(1): $21-26$.

10. Meier GM. (1995). Leading Issues in Economic Development. Oxford (EN): Oxford University Press.

11. Rahmaningsih S and Ari Al. (2013). Cantang Grouper Epinephelus fuscoguttatuslanceolatus Feed and Growth. Ecologya. 13 (2): 25 - 30.

12. Riduwan. (2010). Research Variables Measurement of Scale. Bandung (ID): Alfabeta.

13. Sachoemar SI and Wahjono HD. (2007). Condition of Water Environmental Pollution in Jakarta Bay. Journal of Indonesia Aquaculture. $3(1): 1$ - 14.

14. Soebagio. (2005). Analysis of Policies on the Utilization of Coastal and Marine Space in Kepulauan Seribu Society to Increasing Income Through Cultivation and Tourism Activities. [dissertation]. Bogor (ID): IPB University.

15. Soekartawi. (2002). Basic Principles of Agricultural Economics : Theory and Application. Jakarta (ID): Raja Grafindo Persada.

16. Suarez MDLC. (2001). Trade Creation and Trade Diversion For Mercosur. [dissertation]. Boston (US): Boston University.

17. Sucipto A. (2011). Business Feasibility Studies: Integrative analysis and case studies. Malang (ID): UIN-Maliki Press. 